\title{
Associability of CVC-word pairs and its relation to list difficulty
}

\section{ALEXANDER J. WEARING AND WILLIAM E. MONTAGUE}

Previous data showed that two lists, constructed of seemingly homogeneous materials, were not equivalent. It was hypothesized that the reason for the difference lay in the Associability (AS) of the pairs used in the lists. In this study, AS was determined by the proportion of $50 \mathrm{Ss}$ giving an associative aid to link a pair within 15-sec. The two lists differed significantly in mean $A S$ value and the correlation between AS and errors in learning (previous data) was -.64 , confirming the hypothesis.

There is no longer any question that associative devices are widely used by Ss to facilitate paired associate (PA) learning. A number of studies, such as those by Clark, Lansford, \& Dallenbach (1960), Mattocks, as reported by Underwood \& Schulz (1960, p. 297 ff), Bugelski (1962), Runquist \& Farley (1964), and Goss \& Nodine (1965) say that Ss universally report that they use associative aids in linking items of a pair together. Whenever possible, it seems that an $\mathrm{S}$ will utilize his past language learning to mediate the connections between items.

These linguistic devices, or natural language mediators (NLMs) have been shown to have a strong facilitative relationship with both acquisition and retention (Kiess \& Montague, 1965; Montague, Adams, \& Kiess, 1966; Montague \& Wearing, 1967). However, the presence or absence of NLMs is usually detected by means of a questionnaire administered upon the completion of the experiment. This procedure is open to bias in that there is no indication of whether it emerged sub- sequently or even whether the $\mathrm{S}$ is reporting a NLM because he perceives such reports as being one of the demand characteristics (Orne, 1962) of the experiment. It is also possible that the form and/or content of NLMs may change over trials. Therefore, some independent measure of the likelihood of NLMs being formed is necessary.

Montague \& Kiess (1966) undertook to scale CVC pairs for Associability (AS) in the following manner. Large groups of Ss were presented with CVC pairs for 15 sec. During this time, the Ss wrote down any NLM that they had for the pair. The AS scale value was defined as the proportion of Ss reporting a NLM for each pair. In validating this scale, Montague and Kiess found that AS value variations were associated with reliable differences in learning rate.

In a previous experiment (Montague \& Wearing, 1967), two CVC-word lists (shown in Table 1) were learned by two large groups $(\mathrm{N}=70,95)$ of Ss. The lists were homogeneous with respect to stimulus (CVC) association value, and Thorndike \& Lorge (1944) word count. In spite of this homogeneity, one of the lists was significantly more difficult to learn than the other. Although this difference might have been due to sampling error in the Ss assigned to the groups, it was thought more likely that the difference was produced by AS differences. Therefore, in this study, the pairs used in the previous experiment were scaled for AS by another group of Ss, and then the relation to learning and to the reported NLMs was calculated.

Table 1. List pairs, scaled association value of the stimulus (AV), ${ }^{1}$ response word frequency (WF), ${ }^{2}$ mean number of errors per pair to criterion, associability (AS) value, and proportion of learning methods involving a NLM

\begin{tabular}{|c|c|c|c|c|c|c|c|c|c|c|c|}
\hline $\begin{array}{l}\text { ltems } \\
\text { List } 1\end{array}$ & AV & WF & $\begin{array}{c}\text { Mean No. } \\
\text { Errors } \\
(n=70)\end{array}$ & $\begin{array}{c}\text { AS } \\
\text { Value }\end{array}$ & $\begin{array}{l}\text { roportion } \\
\text { of } \\
\text { NLMs }\end{array}$ & $\begin{array}{l}\text { Items } \\
\text { List } 2\end{array}$ & $A V$ & WF & $\begin{array}{c}\text { Mean No. } \\
\text { Frrors } \\
(n=95)\end{array}$ & $\begin{array}{c}\text { AS } \\
\text { Value }\end{array}$ & $\begin{array}{c}\text { Proportion } \\
\text { of } \\
\text { NLMs }\end{array}$ \\
\hline BIF-THIEF & 25 & 28 & 1.46 & .84 & .67 & VAH-OUIET & 27 & A & 2.31 & .74 & .77 \\
\hline ZOK-EARTH & 24 & $\mathrm{AA}$ & 1.10 & .74 & .63 & ZAS-WHERE & 25 & $\mathrm{AA}$ & 2.01 & .70 & .55 \\
\hline JEH-FRUIT & 25 & $A A$ & 1.90 & .84 & .59 & CUY-BIBLE & 29 & 25 & 1.52 & .60 & .53 \\
\hline FIY-TABLE & 25 & $A A$ & 1.56 & .88 & .57 & GIK-EAGLE & 30 & 38 & 2.04 & .64 & .62 \\
\hline RUQ-MUSIC & 24 & $A A$ & 1.87 & .78 & .61 & PUJ-CARRY & 28 & $A A$ & 2.19 & .66 & .55 \\
\hline TOV-GREEN & 25 & AA & 1.23 & .60 & .49 & YOD-DOORS & 25 & AA & 2.11 & .80 & .40 \\
\hline XAR-BLACK & 25 & $A A$ & 1.94 & .88 & .65 & LEQ-SHORT & 28 & $A A$ & 1.58 & .88 & .82 \\
\hline QES-OCFAN & 26 & $A A$ & 1.37 & .82 & .66 & BUH-STAND & 24 & $A A$ & 2.21 & .68 & .54 \\
\hline MAJ-SWEET & 26 & $\mathrm{AA}$ & 1.66 & .78 & .53 & XIP-SHEEP & 26 & A & 1.77 & .80 & .32 \\
\hline KEB-HEAVY & 25 & $A A$ & 2.24 & .66 & .51 & MIB-STOVE & 27 & 40 & 2.32 & .34 & .33 \\
\hline WUG-SHOES & 27 & $\mathrm{AA}$ & 1.64 & .78 & .71 & QOM-CHILD & 27 & $\mathrm{AA}$ & 1.66 & .80 & .60 \\
\hline NAX-DREAM & 27 & $\mathrm{AA}$ & 2.40 & .70 & .58 & SEJ-SPEAK & 24 & $\mathrm{AA}$ & 1.89 & .62 & .35 \\
\hline Meon & 25.3 & & 1.40 & .79 & .60 & & 26.7 & & 1.95 & .69 & .53 \\
\hline
\end{tabular}

1 Archer, 1960; 2 Thorndike and Lorge, 1944. 
If the AS scale is a valid index, AS should be negatively correlated with acquisition errors, and positive correlated with NLM frequency.

\section{Method}

Subjects. The Ss were 50 paid undergraduates at the University of Illinois.

Procedure. In order to determine the AS values of the stimuli, a slide projector was used to present in random order the 24 pairs shown in Table 1, along with 24 additional pairs of the same type that had been used in other experiments. Each pair was shown separately for a period of $15 \mathrm{sec}$. The Ss were instructed to write down any association that they could think of between the items of each pair, as it was presented. The AS value of each pair was defined as the proportion of Ss who were able to do so.

In Table 1, data from the groups run by Montague \& Wearing (1967) and the AS values obtained in the present study are shown. In the table, the pairs are shown along with the Archer (1960) association value (AV) of each CVC, the Thorndike-Lorge frequency of each word, the mean number of errors made in acquisition, and the proportion of reports involving the use of NLMs for each pair, which was obtained from post-acquisition questionnaires. Significantly more errors were made by the group learning list 2 than that of learning list $1(p<.05)$.

The expectation concerning possible differences in AS values between the lists was confirmed by the results of the present study. The mean AS value for list 2 was significantly less than that for list 1 ( $p<$ $.02)$. The relationship is shown also in a high negative correlation between AS value and number of errors made to criterion on a pair (rho $=-.64, \mathrm{p}<.001$ ).

It was also predicted that items with higher AS values would have had a greater proportion of Ss reporting that they used a NLM in learning the item. These data, obtained in the Montague-Wearing experiment, are shown in the "Proportion of NLMs" column in Table 1. The prediction was supported only weakly. The rank order correlation between AS value and the proportion was in the expected direction but was not significant ( $\mathrm{rho}=.25$ ).

\section{Discussion}

These results allow us to conclude that AS value is indeed a useful predictor of learning difficulty. Even though there are no significant differences between the AVs or the Thorndike-Lorge word frequency counts for the two lists, the differences in learning difficulty can be attributed to AS score differences.

The second prediction, that a strong relation would be found between AS value and proportion of Ss using
NLMs in learning, received little support. Since NLMs and AS values are strongly associated with acquisition rate, the reason for the weak association between the number of NLMs reported and AS value may be that greater opportunity exists for developing NLMs during a series of learning trials than in the task wherein AS was obtained. The AS value was derived from the number of Ss reporting a NLM for a pair within a 15-sec. interval. For some pairs, NLMs may be difficult to generate and require more time. Upon repeated exposure during a series of learning trials, however, more time is available for NLM formation. Therefore, AS value may be more indicative of the speed with which a pair generates a NLM in learning than of the total number generated during learning.

The main point made by this study is that verbal reports about NLMs from one set of Ss are able to predict the learning rate of another set of Ss. Indeed, independently determined AS norms were able to predict performance in a manner impossible using traditional measures.

\section{References}

Archer, E. J. A re-evaluation of the meaningfulness of all possible CVC trigrams. Psychol. Monogr., 1960, 74, No. 10, (Whole No. 497).

Bugelski, B. R. Presentation time, total time, and mediation in paired-associate learning. J. exp. Psychol., 1962, 63, 409-412.

Clark, L. L., Lansford, T. G., \& Dallenbach, K. M. Repetition and associative learning. Amer. J. Psychol., 1960, 73, 22-40.

Goss, A. E., \& Nodine, C. F. Paired-associates learning. New York: Academic Press, 1965.

Kiess, H. O., \& Montague, W. E. Natural language mediators in paired-associate learning. Psychon. Sci., 1965, 3, 549-550.

Montague, W. E., Adams, J. A., \& Kiess, H. O. Forgetting and natural language mediation. J. exp. Psychol., 1966, 72, 829-833.

Montague, W. E., \& Kiess, H. O. The associability of CVC pairs and its relation to learning. Paper presented at the 7 th Annual Meeting, Psychonomic Society, October, 1966.

Montague, W. E., \& Wearing, A. J. The complexity of natural language mediators and its relation to paired-associate learning. Psychon. Sci., 1967, 7, 135-136.

Ome, M. T. On the social psychology of the psychological experiment: With particular reference to demand characteristics and their implications. Amer. Psychologist, 1962, 17, 776-783.

Runquist, W. N., \& Farley, F. H. The use of mediators in the learning of verbal paired-associates. $J$. verbal Learn. verbal Behav., 1964, 3, 280-285.

Thorndike, E. L., \& Lorge, I. The teacher's word book of 30,000 words. New York: Columbia University Press, 1944.

Underwood, B. J., \& Schulz, R. W. Meaningfulness and verbal learning. New York: Lippincott, 1960.

\section{Note}

1. This research was supported in part by the Joint Services Electronics Program (U. S. Army, U. S. Navy, and U. S. Air Force) under Contract No. DA 28043 AMC 00073(E); in part by ONR Nonr-3985(08), and in part by Contract OEC-3-6-058375-0612. 